\title{
The relationship between repetition and depth of processing
}

\author{
ROBERT J. CHABOT, TIMOTHY J. MILLER, and JAMES F. JUOLA \\ University of Kansas, Lawrence, Kansas 66044
}

\begin{abstract}
The relationship between depth of information processing and stimulus repetitions was investigated using a simultaneous category judgment task. Several levels of processing were defined involving (1) physically identical items, (2) physically different but same-name items, (3) different items from the same semantic category, and (4) items from different categories. Stimulus pairs were represented by words and pictures, and each pair was presented one, three, or five times. Response times for categorization judgments increased with the level of processing and decreased with repetitions. Repetitions produced greater facilitation for decisions at deeper levels of processing. In a final incidental recall task, more items were remembered from category-same trials than from same-item trials, but level of processing did not interact with number of presentations. Repetitions produced an equivalent increase in final recall probability for items involved in all decision types, indicating that distributed repetitions can lead to the formation of stronger memory traces at several levels of processing.
\end{abstract}

The role that rote repetition or rehearsal of verbal materials plays in the formation of the memory trace is of current theoretical interest. It has been suggested that repetition plays a dual role in memory: (1) the maintenance of information in primary or short-term memory, and (2) the transfer of information into a secondary or long-term store (Atkinson \& Shiffrin, 1968; Waugh \& Norman, 1965). This conception leads to the prediction that the amount of time that an item is rehearsed in short-term memory should be directly related to its recall probability from long-term memory. Support for this viewpoint has been provided by Rundus (Rundus, 1971; Rundus \& Atkinson, 1970).

Craik (Craik, 1973; Craik \& Lockhart, 1972; Craik \& Tulving, 1975) has offered an alternative framework for information processing models of memory. He suggested that the memory trace is a direct result of the qualitative nature of stimulus encoding operations. For example, a word can be encoded in terms of its visual properties, phonemic properties, semantic associations, or related images depending upon the nature of the task. Information about a stimulus can thus be processed at different levels, with a greater depth of processing usually implying a longer processing time and a greater degree of semantic analysis. The quality of the memory trace depends on the depth of the perceptual analyses of the stimulus, and the resistance to forgetting for a given trace is determined by the degree of stimulus elaboration within a specific encoding domain. Attention, stimulus meaningfulness, and avail-

This work was supported by NSF Grant BMS74-12801 to the third author. We thank Edward M. Duncan, George Kellas, and Thomas $O$. Nelson for their comments on an earlier version of this paper and Robb Gilford for his assistance in preparing the graphs. Reprint requests should be sent to Robert Chabot, Psychology Department, University of Kansas, Lawrence, Kansas 66044. able processing time influence the depth and spread of information activated in the memory system by stimulus encoding processes.

Within the depth of processing framework, rote repetition is associated solely with the maintenance of information at a given level of processing. It is the level of processing and the degree of stimulus elaboration within a level which determine the probability of future recall, rather than the amount of rehearsal per se. Therefore, Craik and Lockhart (1972) have distinguished between two types of perceptual coding. Type I, or maintenance coding, is a function of the amount of repetition and merely prolongs the availability of the item within short-term memory, without leading to the formation of a more permanent memory trace. Type II, or elaboration coding, is a function of the depth of processing and is directly related to memory trace strength, as it can lead to changes in the internal representation of the stimulus.

The function of the amount of maintenance coding on subsequent recall has been investigated by Craik and Watkins (1973). Subjects listened to a series of word lists and were asked to report only the last word presented which began with a particular critical letter defined prior to the start of each list. Thus, they could have ignored words not beginning with the critical letter in short-term memory until the next critical word was presented. The number of intervening noncritical items was manipulated to vary the amount of time that each critical word was held in memory. The results from an unexpected free recall test indicated that the amount of time a word was held in memory had no effect upon its probability of subsequent recall.

Other research has related long-term recall probability to the depth and elaboration of stimulus encoding. Craik and Tulving (1975) manipulated the qualitative nature of encoding operations and measured subsequent 
memory in incidental recall and recognition tasks. Prior to the display of a single word, subjects were asked a question about it which could be answered either "yes" or "no." The types of questions asked were used to manipulate the depth of word encoding as well as the difficulty of the task within the level of analysis. The questions were about the physical structure of the word, its phonemic qualities, or its semantic or categorical properties. It was found that deeper perceptual or semantic analyses led to better performance in both recall and recognition tasks, but the amount of time the task took was not a significant factor.

Using a Posner (1969) same-different task, Rosch (1975) also varied depth of processing and measured recall and recognition on a final unexpected test. Subjects judged whether two simultaneously presented words or pictures were members of the same semantic category. Depth of processing on same trials was manipulated by having physically identical items or different items belonging to the same semantic category. Response times to physically identical stimuli were significantly faster than those to different items belonging to the same semantic category. Subsequent free recall and recognition were greater for those items processed to the category level. These differences were used as evidence that same-category items were processed to a deeper level than physically identical stimuli.

The importance of initial encoding operations for the durability of the memory trace has thus been demonstrated in several studies. Probability of recall increases as the amount of semantic analysis increases. However, the relationship between repetitions within a given level of processing and depth of processing is unclear. Craik and Watkins' (1973) task encouraged rote repetition of the stimuli at a superficial level of processing, as subjects had only to maintain the items in short-term memory. Depth of processing, type of initial encoding, and the amount of repetition were not simultaneously manipulated. The present study was therefore designed to test the hypothesis that repetitions have a greater effect on memory trace strength at deeper levels of processing. The type of stimuli (words and pictures), the level of semantic processing within a same-different task for category membership (two stimuli representing either the same item, and same semantic category, or different categories), and the number of stimulus repetitions were manipulated. The effects of these variables were determined for response latencies in the categorization task as well as for percent recall in a final incidental memory task.

\section{METHOD}

\section{Subjects}

The subjects were 24 introductory psychology students at the University of Kansas who participated for course credit. All subjects had normal or corrected to normal vision and were native English speakers.

\section{Materials}

Each stimulus consisted of a pair of items selected from a pool of 96 different items previously used by Juola, Taylor, and Young (1974) and from the Peabody Picture Vocabulary Test for children (Dunn, 1959). The stimuli were words and simple outline drawings of the objects named by the words. The words were all common nouns and ranged in length from 3 to 10 letters. The items used were selected so that the words were approximately equal in frequency of occurrence within each category. The corresponding pictures were previously judged to be easily and uniquely identifiable.

The stimulus set consisted of 90 words and 90 pictures from 10 distinct categories, with 9 members per category. In addition, there were 19 words and their corresponding pictures drawn from three different categories used for practice trials. All stimulus words and their respective categories are presented in Table 1.

The stimuli were placed on $15.2 \times 22.9 \mathrm{~cm}$ white cards for

Table 1

Category Names and Exemplars Used in Experimental and Practice Trials

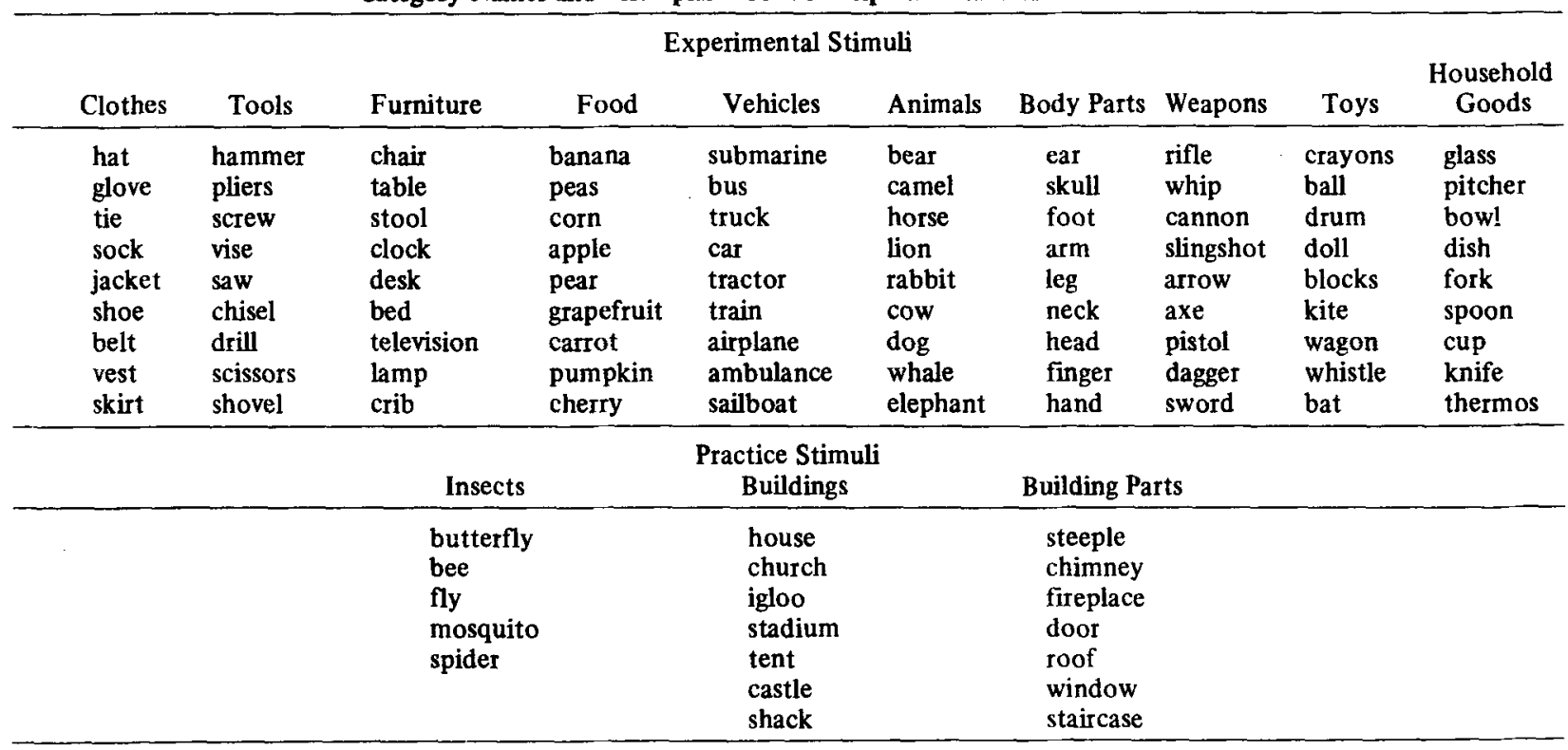


presentation in an Iconix four-field tachistoscope. Each card contained two stimuli centered side by side in the field of view when seen in the tachistoscope. The stimuli were two words (WW), two pictures (PP), or a word and a picture (WP), and were approximately $1.3 \mathrm{~cm}$ apart. The words were typed in Orator typeface with an IBM Selectric typewriter, and they varied in length from 1 to $2.5 \mathrm{~cm}$ and subtended visual angles ranging from .7 to $1.7 \mathrm{deg}$. Xerox copies of the pictures were affixed to the cards, and they varied in diameter from 1.5 to $3 \mathrm{~cm}$ and subtended visual angles ranging from 1.0 to $2.1 \mathrm{deg}$.

The subjects' task was to respond either "same" or "different" depending on the relationship between the two stimuli. The different levels of processing were: (1) Same item: Either the same word or picture was presented on both sides (a physical match), or the word and the picture depicting that word were presented together (a name match). (2) Same category: The names, pictures, or name and picture of two members of the same semantic category were presented. (3) Different categories: The names, pictures, or a name and a picture of two members of different categories were presented. Within the word and picture conditions, the word and picture appeared equally often on the left and right sides.

\section{Design}

The 90 stimulus items were randomly divided into three groups, such that there were 18 pairs of items for each level of processing. These were used to produce a set of 162 experimental trials. Within each level, one-third of the pairs were presented once, one-third three times, and one-third five times. The ordering of the pairs within the trial set was random, with the constraint that each third of the $\mathbf{1 6 2}$ trials contained six of the single-repetition pairs, all 18 of the pairs presented three times, and 30 trials involving pairs presented five times. The word-word (WW), picture-picture (PP), and word-picture (WP) stimulus pairs were completely crossed with all other conditions. This entire procedure was repeated four times to make up four different trial sets. Each of these was then randomized three times, within the above constraints, to yield 12 different sequences of experimental trials that were each used for two subjects.

\section{Procedure}

Subjects were tested individually. Each subject read the instructions for the categorization task and was given 18 practice trials followed by the 162 experimental trials. At the start of each trial the subject placed his index fingers on two response buttons mounted on a panel approximately $2 \mathrm{~cm}$ apart. For half of the subjects, the right index finger was used for the same responses and the left finger for different responses. These conditions were reversed for the other subjects. It was stressed to the subjects that they should respond quickly and accurately. Preceding each trial, the subject looked into the tachistoscope and fixated a black cross which represented the midpoint between the two stimuli. He then pressed a footswitch, and $500 \mathrm{msec}$ later the stimuli appeared for $500 \mathrm{msec}$. Subjects were then required to respond either same or different, depending upon whether the two stimuli were members of the same semantic category, by pressing the appropriate response button. After the experimental trials the subjects were asked to cross out the vowels from two lists of words and nonwords typed in mixed-case print. After the completion of this task, which lasted approximately $5 \mathrm{~min}$, all subjects were given exactly $10 \mathrm{~min}$ to recall the names of all the stimulus items that they had seen. This recall task was not announced in advance.

\section{RESULTS AND DISCUSSION}

\section{Reaction Time Data}

Figure 1 presents mean reaction times across subjects for all stimulus and decision conditions plotted as a function of number of presentations. Three separate analyses of variance were applied to the reaction time data: one to items presented once, another to items presented three times, and a third to items presented five times. Conventional $F$ tests were used in all cases, as the set of categories and exemplars used virtually exhausted the population of semantic categories for which a sufficiently large number of easily picturable and common exemplars exists. Furthermore, these stimuli were not randomly chosen, and if they were to be treated as a random sample from some larger population, it is not clear exactly what this population would be (see Wike \& Church, in press). The two factors in the analysis for items presented once were Decision
Figure 1. Mean reaction times for all stimulus and decision types plotted as functions of number of presentations.

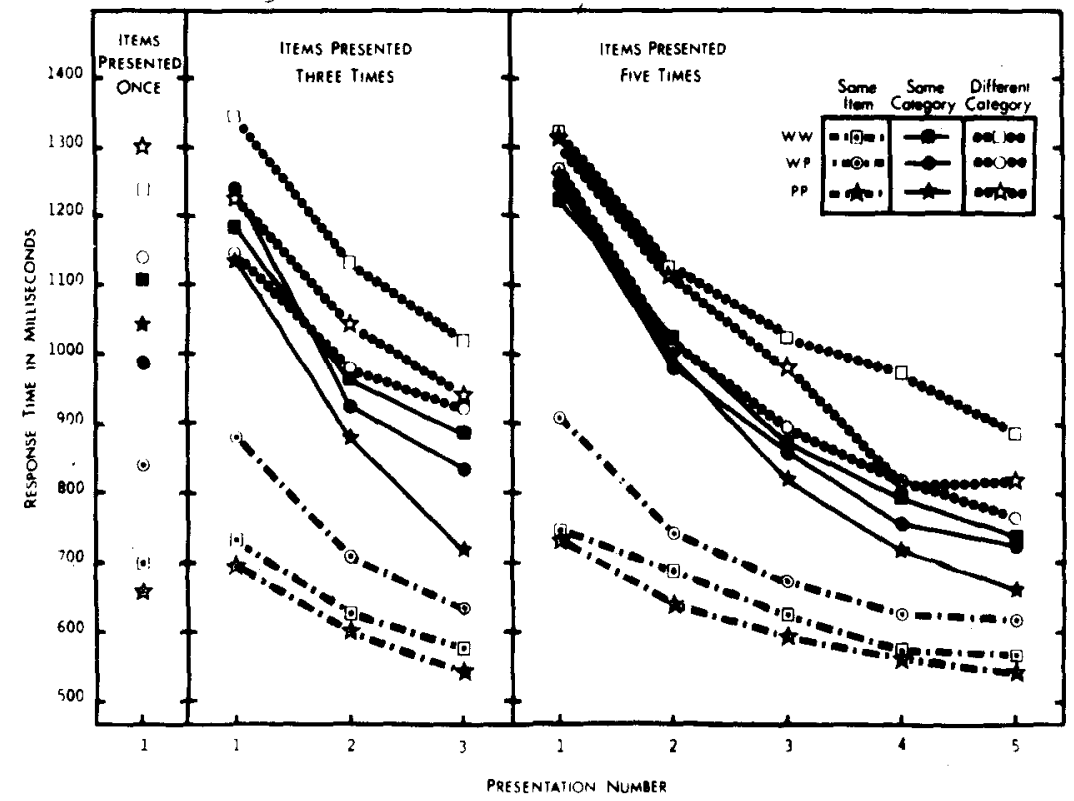


Type (same item, same category, and different categories) and Stimulus Type (WW, WP, and PP). There was a significant main effect of Decision Type $[\mathrm{F}(2,46)$ $=76.2, \mathrm{MSe}=5.8 \times 10^{6}, \mathrm{p}<.001 \mathrm{~J}$, and multiple comparisons using the Tukey $b$ procedure (Winer, 1971) indicated that same-item responses were significantly faster than category-same and different responses and that category-same responses were faster than different responses $(\mathrm{p}<.01)$. A significant interaction of Decision Type by Stimulus Type was obtained $[F(4,92)=3.96$, MSe $\left.=5.7 \times 10^{6}, p<.01\right]$. Multiple comparisons indicated no significant differences between WW, WP, and PP stimulus pairs at any decision level, but the order of the pairs was different in each decision condition. This result was expected in that $W W$ and $P P$ items represented physical matches on same-item trials, whereas WP items matched in name only (Posner, 1969). Faster responses to WP trials in the different-category conditions might be due to the fact that a "different" response is more compatible with the presentation of two stimuli that also differ in form.

For items presented three times there were three factors in the analysis: Decision Type, Stimulus Type, and Number of Presentations. There was a significant main effect of Decision Type $[F(2,46)=96.3$, MSe $=$ $\left.10.4 \times 10^{6}, \mathrm{p}<.001\right]$. Multiple comparisons again indicated that different responses were slower than category-same responses, which were slower than sameitem responses $(p<.01)$. There was a significant main effect of Stimulus Type $[\mathrm{F}(2,46)=6.24, \mathrm{MSe}=5.1$ $\left.X 10^{6}, p<.01\right]$, with responses to PP items being faster than those to WP items $(p<.05)$ and WW items $(p<.01)$. There were no significant differences between response times to WW and WP pairs. The main effect of Repetition was significant $\left[\mathrm{F}(2,46)=84.5, \mathrm{MSe}=5.2 \times 10^{6}\right.$, $\mathrm{p}<.001]$, with responses to items presented for the third time being faster than responses to second presentations and responses on second presentations faster than those of first presentations $(p<.01)$. As was found for the items presented only once, there was a significant Decision Type by Stimulus Type interaction $[\mathrm{F}(4,92)=$ $\left.8.3, \mathrm{MSe}=3.8 \times 10^{6}, \mathrm{p}<.01\right]$. The WP responses were the slowest for the same-item condition $(p<.01)$ and responses to the $\mathrm{PP}$ items were fastest in the categorysame condition $(\mathrm{p}<.05)$. For the different-category condition, response times to WP and PP pairs were not significantly different, but responses to WP pairs were significantly faster than those for WW items $(p<.01)$ and responses to PP pairs were faster than responses to $W W$ items $(p<.05)$. Finally, there was a significant Decision Type by Repetition interaction $[F(4,92)=7.22$, $\left.\mathrm{MSe}=2.4 \times 10^{6}, \mathrm{p}<.01\right]$. For responses to samename items there was no significant difference between second and third presentations, whereas for category. same and different responses there was a significant decrease in response time $(p<.01)$.

For items presented five times, the factors in the analysis corresponded to Decision Type, Stimulus Type, and Number of Repetitions. There was a significant main effect of Decision Type $[F(2,46)=189.4$, $\left.\mathrm{MSe}=6.4 \times 10^{6}, \mathrm{p}<.001\right]$. Multiple comparisons indicated that same-item decisions were faster than category-same decisions and that category-same decisions were faster than different decisions $(p<.01)$. There was a significant main effect of Repetitions $\left[F(4,92)=87.8, \quad \mathrm{MSe}=6.8 \times 10^{6}, \quad \mathrm{p}<.001\right]$, with reaction time decreasing as the number of repetitions increased. There was again a significant Decision Type by Stimulus Type interaction $[\mathrm{F}(4,92=5.25$, MSe $=$ $\left.5.9 \times 10^{6}, \mathrm{p}<.01\right]$, with WP trials producing the slowest responses for same items and the fastest responses for different-category items. There was also a significant Decision Type by Repetitions interaction $\left[\mathrm{F}(8,184)=14.1, \mathrm{MSe}=2.32 \times 10^{6}, \mathrm{p}<.001\right]$. For same items there was no significant effect for Repetitions after the third presentation, whereas for both the same-category and different-category decisions there was a significant effect of Repetitions through four presentations $(p<.01)$.

The overall error rate on the categorization task was $8.2 \%$. The error rate for physical-identical matches and same-name matches was $.5 \%$, while it was $11 \%$ for the category-same decisions and $12 \%$ for different-category decisions. There was no interaction across stimulus conditions, as the error rates for WW, WP, and PP pairs were $8.2 \%, 7.9 \%$, and $7.9 \%$, respectively. In addition, there was no interaction across repetitions. Although more errors were made on initial presentations of repeated items $(11.1 \%)$ than on repeated presentations $(7.4 \%)$, this difference was not significant, and speed-accuracy trade-offs could not have accounted for the observed Repetition by Decision Type interaction in the reaction time data.

\section{Incidental Recall Data}

Figure 2 presents percent correct free recall as a function of number of presentations for each stimulus type and decision level. An analysis of variance was performed upon the arc-sine transformations of the percentages of items correctly recalled in the unexpected free recall test. The analysis was a 3 by 3 by 3 withinfactors design, with factors corresponding to depth of processing (same-item, category-same, and differentcategory decisions), number of presentations (one, three, five), and stimulus type (WW, WP, PP). There was a significant main effect of Depth $[\mathrm{F}(1,46)=7.6, \mathrm{MSe}=$ $.88, \mathrm{p}<.01]$. Multiple comparisons indicated that category-same items were remembered significantly better than same items and different-category items $(p<.01)$. There was no significant difference in recall between same items and different-category items. The main effect of Repetitions was significant $[F(2,46)=$ $70.2, \mathrm{MSe}=.66, \mathrm{p}<.001]$, with items presented five times recalled significantly better than those presented three times $(p<.05)$, and items presented three times recalled significantly better than items presented once 


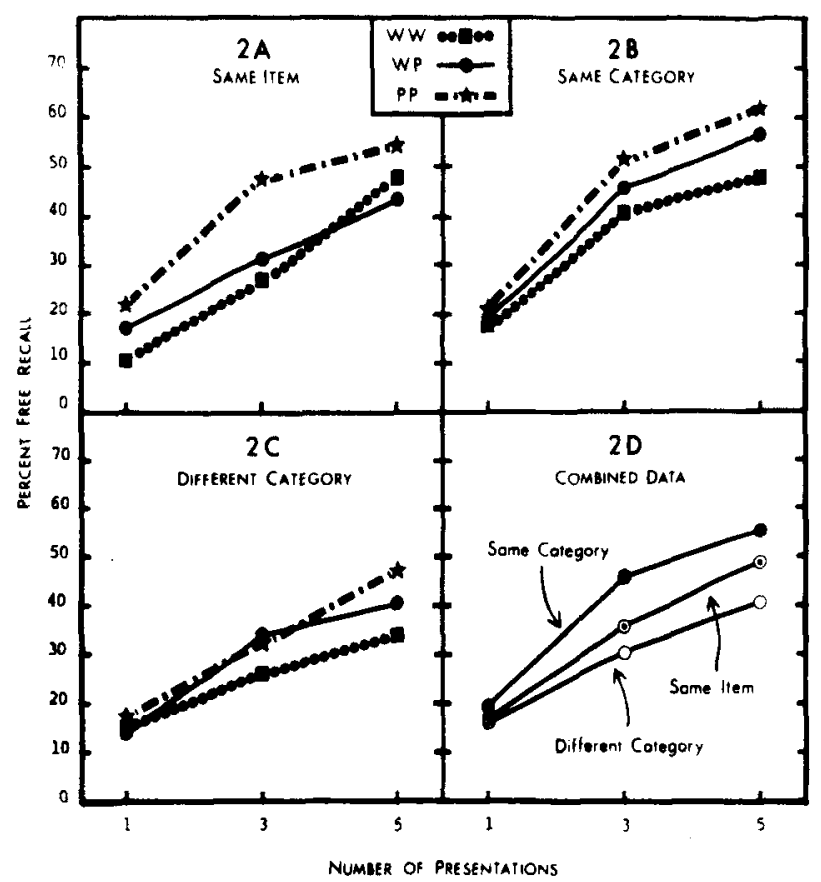

Figure 2. Percent correct free recall for each stimulus and decision type plotted as a function of number of presentations.

$(p<.01)$. There was a significant main effect of Stimulus Type $[F(2,46)=4.56, \quad M S e=1.04, p<.05]$; Multiple comparisons indicated no significant difference in recall for items presented in WW, WP, or PP stimulus pairs. However, an additional $t$ test was done comparing free recall for all items presented only as words and all items presented only as pictures. Picture stimuli were recalled significantly more often often than words $[\mathrm{t}(23)=2.85, \mathrm{p}<.01]$. There were no significant interactions. Figure 2 (Panel D) presents percent correct free recall for items at different levels of processing as a function of number of presentations.

\section{GENERAL DISCUSSION}

The response time data provide supportive evidence for a depth of processing analysis of stimulus encoding and memory. At all repetition levels there was a significant effect of decision type, with responses to same items being faster than those for category-same items, which were faster than different responses. These differences were maintained across repetitions, which indicates continued differential processing within the three conditions despite several stimulus repetitions. The Decision Type by Repetition interaction demonstrated that repetitions have a stronger effect on category-same and different-category decisions than on decisions involving same-item pairs. Repetition had a smaller effect on same-item responses, as there was no effect after the first repetition for items presented three times and no effect after two repetitions for items presented five times. However, for category-same and different-category items, there were significant effects of repetiton up to four presentations for those items presented five times

It is possible that two or three presentations of same items results in their being processed as rapidly as possible, and thus further repetitions cannot result in response times below this floor value. However, it is clear that repetitions have a larger overall effect in the other conditions, and that the effect of repetitions continues over more presentations than for same items. Whether or not response times for same-category items and different items would eventually reach the same asymptotic value as same items is not determinable from our data. Thus, we assume that within-level processing was differentially affected by repetitions. At least for the relatively short time intervals involved during the test sequence, repetitions facilitated response times more for decisions based on semantic information than for those based on same-name or same-physicalform information.

The incidental free recall data also offer support for the depth of processing analysis. However, a purely maintenance function for within-level repetition does not seem tenable, at least for repetitions separated by intervening events. One of the strongest effects in the present experiment was that of repetition on later incidental recall. At all levels of processing tested, repetition had a powerful effect, with a greater number of repetitions leading to a greater proportion recalled. However, this proportional increase was the same for all depths of processing conditions, resulting in no interaction between repetitions and processing level.

The present results are inconsistent with the finding of no memory increment for continuous within-level repetitions reported by Craik and Lockhart (1972) and Craik and Watkins (1973). It seems likely that repetitions within a given level of processing have a direct effect on the probability of subsequent incidental recall as long as the repetitions are distributed. The response time data support the conclusion that each presentation of a pair of items resulted in processing them to a level appropriate to the stimulus and decision type, as response time differences were maintained across repetitions.

The present data also support a depth of processing approach to the establishment of memory trace strength. Category-same items were recalled significantly better than same items. It had been expected that different items would also be recalled better than same items, since they resulted in the slowest decision times and thus were assumed to have been processed to the deepest level. Craik and Tulving (1975) reported similar results, finding that different items were recalled significantly less often than same items. Although it had been assumed that both category-same items and different items would be processed to the same semantic level, the results indicated that the type of processing must differ. As Craik and Tulving (1975) and Schulman (1974) have suggested, stimulus compatibility with the encoding dimensions might play a role in memory trace 
formation. For example, when a same-category decision is made, the two stimuli form a coherent semantic unit with the category label, thus leading to the formation of an effective memory cue (the category name) for later recall. However, when a different-category decision is made, the unit formed is more complex; i.e., it contains more information (including, perhaps, the category names) and, therefore, leads to the formation of a less effective memory code. This explanation is supported by the verbal reports of the subjects, who indicated that they attempted to recall the category labels as an aid in recalling the actual stimuli.

The results demonstrated better incidental learning for pictorial stimuli than for words. Similar results have been reported by Rosch (1975) and by Snodgrass and McClure (1975). Paivio's (1971) dual coding hypothesis suggests that, since the pictures were easily nameable and imageable, they benefited from the establishment of visual and verbal processing codes, which in tum led to stronger memory traces. Snodgrass and McClure (1975) found no difference in recognition when subjects were asked to encode pictures in terms of visual images or merely in terms of their names. However, subjects did show better recognition for words after having encoded the information by using visual imagery for words than when they were encoded only in terms of their names. It therefore appears that pictures are naturaily encoded in terms of both visual and name codes, whereas words are generally encoded only verbally, thus leading to their inferior recall when compared with pictures.

In conclusion, the present study was generally supportive of a depth of processing approach to memory. Greater semantic analysis leads to the formation of stronger memory traces and within-level repetition can effect subsequent long-term recall. Over the short term, response times on the categorization task were differentially facilitated by repetitions, depending upon the level of the category match or mismatch. However, in the final recall data, the repetition effect did not interact with the level of initial processing. These results indicate that the memory trace can be strengthened by repetitions at various processing levels and that categorization judgments and free recall are differentially affected by within-level repetitions.

\section{REFERENCES}

Atkinson, R. C., \& Shiffrin, R. M. Human memory: A proposed system and its control processes. In K. W. Spence \& J. T. Spence (Eds.), The psychology of learming and motivation: Advances in research and theory, II. New York: Academic Press, 1968. Pp. 89-195.

CraIk, F. M. A "level of analysis" view of memory. In P. Pliner, L. Krames, \& T. Alloway (Eds.), Communication and affect: Thought and language. New York: Academic Press, 1973.

Craik, F. M., \& Lockhart, R. S. Levels of processing: A framework for memory research. Journal of Verbal Léarning and Verbal Behavior, 1972, 11, 671-684.

Craik, F. M., \& Tulving, E. Depth of processing and the retention of words in episodic memory. Journal of Experimental Psychology: General, 1975, 104, 268-294.

Craik, F. M., \& Watkins, M. J. The role of rehearsal in short term memory. Journal of Verbal Learning and Verbal Behavior, 1973, 12, 599-607.

Dunn, L. M. Peabody picture vocabulary test. Circle Pines, Minn: American Guidance Service, 1959.

Juola, J. F., TAYlor, G. A., \& Young, M. E. Stimulus encoding and decision processes in recognition memory. Journal of Experimental Psychology, 1974, 102, 1108-1115.

Paivio, A. Imagery and verbal processes. New York: Holt, Rinehart, \& Winston, 1971.

Posner, M. I. Abstraction and the process of recognition. In G. H. Bower \& J. T. Spence (Eds.), The psychology of learning and motivation: Advances in learning and theory, III. New York: McGraw-Hill, 1969. Pp. 152-179.

Rosch, E. Cognitive representation of semantic categories. Journal of Experimental Psychology: General, 1975, 104, 192-235.

Rundus, D. Analyses of rehearsal processes in free recall. Journal of Experimental Psychology, 1971, 89, 63-77.

Rundus, D., \& Atrinson, R. C. Rehearsal processes in free recall: A procedure for direct observation. Journal of Verbal Learning and Verbal Behavior, 1970, 9, 99-105.

Schulman, A. I. Memory for words recently classified. Memory \& Cognition, 1974, 2, 47-52.

Snodgrass, J. G., \& McClure, P. Storage and retrieval properties of dual codes for pictures and words in recognition memory. Journal of Experimental Psychology: Human Learning and Memory, 1975, 5, 521-529.

Waugh, N. C., \& Norman, R. A. Primary memory. Psychological Review, 1965, 72, 89-104.

WiKe, E. L., \& Church, J. D. Comments on Clark's "The language-as-fixed-effect fallacy." Journal of Verbal Learning and Verbal Behavior, in press.

WINER, B. J. Statistical principles in experimental design (2nd ed.). New York: McGraw-Hill, 1971.

(Received for publication February 9, 1976; revision accepted April 1, 1976.) 